\title{
Effect of three different doses of intrathecal dexmedetomidine on subarachnoid block: a prospective randomized double-blind trial
}

\author{
Ashita Mowar, MD, DA ${ }^{1}$, Vishwadeep Singh, MD² $\bowtie$, Akhilesh Pahade, MD, PDCC $\bowtie$, \\ Geeta Karki, MD $\triangle$ \\ Author affiliation: \\ 1. Assistant Professor of Anesthesiology, Shri Ram Murti Smarak Institute of Medical Sciences, Bareilly - Nainital Rd, Rama \\ Murti Nagar, Bhoji Pura, Uttar Pradesh 243202, India \\ 2. Associate Professor of Anesthesiology, Shri Ram Murti Smarak Institute of Medical Sciences, Bareilly - Nainital Rd, Rama \\ Murti Nagar, Bhoji Pura, Uttar Pradesh 243202, India \\ 3. Professor of Anesthesiology, Shri Ram Murti Smarak Institute of Medical Sciences, Bareilly - Nainital Rd, Rama Murti \\ Nagar, Bhoji Pura, Uttar Pradesh 243202, India \\ Correspondence: Dr. Ashita Mowar; E-mail: drash.royals@gmail.com; Mob: +91 9568578724
}

\section{Abstract}

Background: Dexmedetomidine has increasingly been used in regional anesthesia as an adjuvant, but there is still no consensus on the optimum dose when it is used intrathecally. We conducted this study to elucidate the doseresponse relation between three different doses of intrathecal dexmedetomidine $(2.5,5$, or $10 \mu \mathrm{g})$ as an adjuvant to $0.5 \%$ hyperbaric bupivacaine in patients undergoing elective lower abdominal and lower limb surgeries.

Methodology: 90 patients, aged 18-60 y, were randomized into three groups of 30 patients each. Group A received $0.5 \%$ hyperbaric bupivacaine $12.5 \mathrm{mg}(2.5 \mathrm{ml})$ with $2.5 \mu \mathrm{g}$ dexmedetomidine, Group B received $5 \mu \mathrm{g}$ dexmedetomidine with bupivacaine, and Group $\mathrm{C}$ received $10 \mu \mathrm{g}$ dexmedetomidine with bupivacaine. Duration of the spinal sensory blockade (primary outcome), onset of the blockade, time to rescue analgesia, level of sedation, duration of motor blockade, comparison of hemodynamic variables and complications, if any were assessed.

Results: There was a significant dose dependent prolongation of sensory block; Group A - 250.67 \pm 51.39 , Group B $286 \pm 52.76$, and Group C - $351.00 \pm 47.00 \mathrm{~min}$; $(\mathrm{p}<0.001)$, motor block; Group A - $255.53 \pm 44.25$, Group B - $312 \pm$ 29.64 , and Group C $-361.4 \pm 16.14 \mathrm{~min}(p<0.001)$. Time to two segment regression was $132.33 \pm 48.29,148.77 \pm$ $48.89,171.57 \pm 25.46 \mathrm{~min}(p=0.002)$ and time for rescue analgesia was $351.33 \pm 101.19,472.00 \pm 24.41,738.00 \pm$ $67.79 \mathrm{~min}(\mathrm{p}<0.001)$. VAS was significantly low in Group C $(\mathrm{p}<0.05)$. Intergroup hemodynamic parameters were comparable ( $p>0.05$ ) without any appreciable side effects.

Conclusion: Spinal dexmedetomidine increases the sensory and motor block durations as well as time to first analgesic use, and decreases analgesic consumption in a dose-dependent manner, when used with hyperbaric bupivacaine.

Abbreviations: IT - Intrathecal; ITD - Intrathecal Dexmedetomidine; SAB - Subarachnoid Block; VAS - Visual Analogue Scale; BMI - Body Mass Index; NIBP - Non-Invasive Blood Pressure; RSS - Ramsay Sedation Score; TSSR - Two segment sensory regression; ANOVA - Analysis of Variance; OSB - Onset of sensory block, TSSRT - Two segment sensory regression time; Duration of sensory blockade; OMB - Onset of motor block; DMB - Duration of motor blockade

Key words: Dexmedetomidine; Bupivacaine; Anesthesia, Spinal; Dexmedetomidine; Post-operative analgesia

Citation: Mowar A, Singh V, Pahade A, Karki G. Effect of three different doses of intrathecal dexmedetomidine on subarachnoid block: a prospective randomized double-blind trial. Anaesth. pain intensive care 2021;26(1):8-13; DOI: 10.35975/apic.v26i1.1759

Received: July 24, 2021, Reviewed: November 18, 2021, Accepted: November 28, 2021 


\section{Introduction}

Pain is inherent to all surgeries resulting in significant misery and anguish. Perioperative pain management has been a major challenge for the anesthesiologists and there has been a constant struggle to bring out the best possible analgesic technique with least side effects. ${ }^{1}$

Intrathecal (IT) adjuvants are being used to prolong the duration of spinal anesthesia as well as postoperative analgesia, thereby reducing the requirement of postoperative supplemental analgesics. ${ }^{2}$ The incorporation of adjuvants also lowers the required dose of the local anesthetic and hence its associated side effects. The adjuvants commonly used belong to different classes of drugs with different antinociceptive mechanisms. ${ }^{3}$

Dexmedetomidine is selective alpha-2 agonist with favorable analgesic, sedative, anxiolytic, and sympatholytic features. ${ }^{3}$ Researchers have used dexmedetomidine intrathecally in varying doses with varying results. Despite extensive research; no consensus on optimal dose of intrathecal dexmedetomidine exists, since with higher doses there is better intraoperative and post-operative analgesia, but there is an increased likelihood of hemodynamic disturbances., ${ }^{4,5}$ This prompted us to conduct this research to study varying doses of intrathecal dexmedetomidine so as to compare the prolongation of sensory and motor block duration with dosage ranging from as low as $2.5 \mu \mathrm{g}$ to as high as $10 \mu \mathrm{g}$ as adjuvant along with $0.5 \%$ hyperbaric bupivacaine. Anticipated benefits/outcomes included prolongation of sensory and motor block with reduced/ delayed need of rescue analgesics in the post-operative period and with reduced intraoperative and postoperative side effects.

The primary objective was to ascertain a safe IT dexmedetomidine dose for patients undergoing elective lower abdominal and lower limb surgeries, while analyzing sensory and motor block characteristics with different drug combinations. Secondary outcome measures included risk assessment in terms of level of sedation, comparison of hemodynamic parameters and complications if any.

\section{Methodology}

This prospective, interventional, double-blind, randomized, clinical study was conducted, from October 2019 to July 2020, in accordance with the Helsinki Protocol after written informed consent from all patients and approval from the scientific committee and institutional ethical committee (IEC/2018-19/214).

Ninety patients, ASA physical status I and II, aged 18$60 \mathrm{y}$ of either sex, undergoing elective lower abdominal and lower limb surgeries under planned subarachnoid block (SAB) were enrolled in the study. Exclusion criteria included patient refusal, contraindication to SAB, hypersensitivity to the drugs being evaluated, Body Mass Index (BMI) more than $40 \mathrm{~kg} / \mathrm{m}^{2}$, pregnancy, significant comorbid conditions like uncontrolled hypertension, congestive heart failure, myocardial infarction in the past 6 months, heart block, fixed cardiac output lesions. Cases which needed intraoperative conversion to general anesthesia were also excluded.

Thirty patients were randomly allocated using sealed envelope technique into three groups; Group A $(0.5 \%$ hyperbaric bupivacaine $12.5 \mathrm{mg}+$ dexmedetomidine 2.5 $\mu \mathrm{g})$, Group B (0.5\% hyperbaric bupivacaine $12.5 \mathrm{mg}+$ dexmedetomidine $5 \mu \mathrm{g}$ and Group $\mathrm{C}(0.5 \%$ hyperbaric bupivacaine $12.5 \mathrm{mg}+$ dexmedetomidine $10 \mu \mathrm{g}$ ).

A detailed pre-anesthetic checkup was conducted a day prior to the planned surgery and included an elaborate history of current and coexisting illnesses, detailed general, systemic, airway examinations and all pertinent investigations as per institutional protocol were conducted and reviewed. All patients were explained about Visual Analog Scale (VAS). Tablet alprazolam $0.25 \mathrm{mg}$ and tablet ranitidine $150 \mathrm{mg}$ were given as premedication night before and on the morning of surgery to all patients.

After applying standard monitors such as non-invasive blood pressure (NIBP), heart rate (HR), peripheral oxygen saturation $\left(\mathrm{SpO}_{2}\right)$ and electrocardiography, initial baseline data was recorded. Intravenous (IV) access was secured and crystalloid solution $15 \mathrm{ml} / \mathrm{kg}$ was infused to each patient prior to SAB. The SAB was performed in the standard method, and the study drugs were injected into the spinal theca.

Pain was assessed using VAS hourly for the first $4 \mathrm{~h}$, then 4 hourly for the next $8 \mathrm{~h}$, and at $24 \mathrm{~h}$ postoperatively. Inj. tramadol $1.5 \mathrm{mg} / \mathrm{kg}$ slow IV was given as a rescue analgesic when the VAS exceeded 4. Time for the first rescue analgesic and the total number of rescue analgesics administered over $24 \mathrm{~h}$ were noted. All time durations were calculated considering time of completion of IT injection as time zero. The time of skin incision and completion of skin closure were noted and the duration of surgery calculated in min.

Ramsay sedation score (RSS) was used for assessing sedation. Sedation score for the patients were assessed hourly till $4 \mathrm{~h}$ after surgery and then at $8 \mathrm{~h}, 12 \mathrm{~h}$ and 24 $\mathrm{h}$ post-spinal injection. In the postoperative period Bromage score and sensory level were assessed every 15 min until recovery to Bromage 0 and two segment sensory regression (TSSR), respectively.

Statistical analysis: The sample size was determined by using the duration of the spinal sensory blockade to compare the effectiveness among groups. We assumed 
difference of 50 min in duration of the spinal sensory blockade between any two groups as clinically significant, thus sample size of 47 patients per group were considered necessary to detect statistical significances with an effect size of 0.83 at alpha 0.05 and power of $90 \%$.

Statistical testing system utilized was the statistical package for the social science version (SPSS) 17.0. Continuous variables being presented as mean \pm SD or median (IQR) for non-normally distributed data. Categorical variables were expressed as frequencies and percentages.

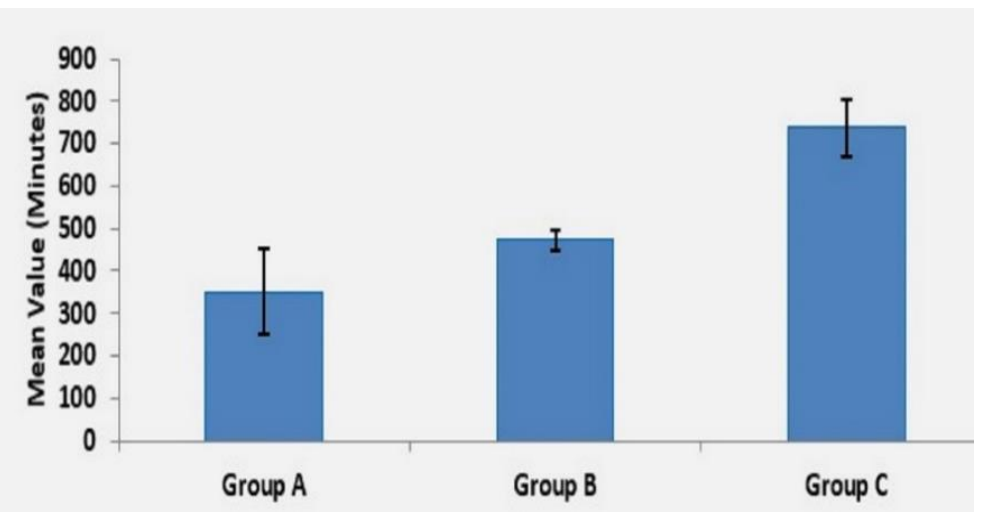

Normally distributed continuous variable comparison between the groups was performed using ANOVA. If the $F$ value was significant, Tukey or Tamhane's T2 multiple comparison test was used to assess the differences between the individual groups. Nominal categorical data between the groups was compared by utilizing Chi-squared test or Fisher's exact test as appropriate.

Figure 1: Comparative time for rescue analgesia

\begin{tabular}{llllll}
\multicolumn{4}{l}{ Table 1: Demographic data of the participants } \\
Parameter & & Group A & Group B & Group C & P \\
Mean age & & 44.33 & 46.57 & 45.57 & 0.541 \\
Gender & Male & $40.0 \%$ & $43.3 \%$ & $53.3 \%$ & 0.559 \\
& Female & $60.0 \%$ & $56.7 \%$ & $46.7 \%$ & \\
ASA status & ASA 1 & $43.3 \%$ & $70.0 \%$ & $60.0 \%$ & 0.107 \\
& ASA 2 & $56.7 \%$ & $30.0 \%$ & $40.0 \%$ &
\end{tabular}

Non-normal distribution continuous variables were compared using Kruskal Wallis test and further paired comparisons were done using Mann Whitney-U test. For all statistical tests, a $\mathrm{p}$ value under 0.05 indicated a significant difference.

\section{Results}

The patients enrolled into the study were divided into three groups. All three groups were comparable with respect to demographic profile, ASA (American Society of Anesthesiologists) physical $40.0 \%$ were associated with $\mathrm{T} 8$ sensory level and among C Group subjects $40.0 \%$ were associated with T4 sensory level. The above levels were statistically very highly significant $(\mathrm{P}<0.001)$ (Table 3$)$. There was a highly status and operative time (Table 1). Baseline preoperative pain, sedation scores and hemodynamic data did not differ significantly among the three groups $(\mathrm{P}>0.5)$.

There was a significant statistical difference $(\mathrm{P}<0.5)$ among groups regarding onset of sensory block (OSB), as Group $C$ showed onset after $194.93 \pm 12.14 \mathrm{sec}$, while Group B showed an OSB after $204.67 \pm 13.64 \mathrm{sec}$ and Group A it was $231.40 \pm 28.44 \mathrm{sec}$ (Table 2).

The highest sensory level achieved for the three groups A, B, C were T6 (26.7\%), T4 (3.3\%) and T4 (40.0\%) respectively. Among the $\mathrm{A}$ and $\mathrm{B}$ groups $63.3 \%$ and

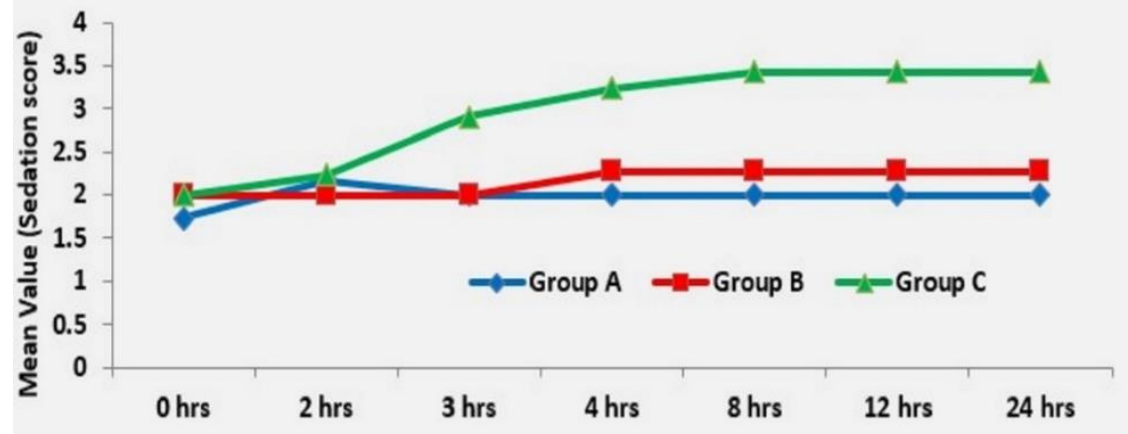

Figure 2: Comparative sedation score in three groups

significant difference with respect to two segment sensory regression time (TSSRT) between Group A vs. $\mathrm{C}(\mathrm{P}<0.001), 2$ segment sensory regression time in Group A was $132.33 \pm 48.29$ min, Group B was 148.77 $\pm 48.89 \mathrm{~min}$ and Group C $171.57 \pm 25.46 \mathrm{~min}$ (Table 2).

Significant dose related prolongation in the duration of sensory blockade (DSB) amongst the three groups was seen $(\mathrm{p}<0.001)$ (Table 2$)$.

The onset of motor block (OMB) was significantly earlier in Group $\mathrm{C}$ compared with Group A $(\mathrm{P}<0.001)$ and Group B vs C ( $\mathrm{P}<0.001)$, however there was no significant difference between Group A vs. B $(\mathrm{P}=0.677)$ 


\begin{tabular}{|c|c|c|c|c|c|c|c|}
\hline Block times & Group A & Group B & Group C & $\begin{array}{l}P \\
\text { Value }\end{array}$ & $\begin{array}{l}\text { Group A } \\
\text { vs. B }\end{array}$ & $\begin{array}{l}\text { Group A } \\
\text { vs. C }\end{array}$ & $\begin{array}{l}\text { Group B } \\
\text { vs. C }\end{array}$ \\
\hline $\begin{array}{l}\text { Onset of sensory block } \\
\text { (sec) }\end{array}$ & $\begin{array}{l}231.40 \pm \\
28.44\end{array}$ & $\begin{array}{l}204.67 \pm \\
13.64\end{array}$ & $\begin{array}{l}194.93 \pm \\
12.14\end{array}$ & $\begin{array}{l}<.001 \\
0\end{array}$ & $<0.001$ & $<0.001$ & 0.015 \\
\hline $\begin{array}{l}\text { Duration of sensory } \\
\text { block (min) }\end{array}$ & $\begin{array}{l}250.67 \pm \\
51.39\end{array}$ & $\begin{array}{l}286 \pm \\
52.76\end{array}$ & $\begin{array}{l}351.00 \pm \\
47.00\end{array}$ & $<0.001$ & 0.033 & $<0.001$ & $<0.001$ \\
\hline $\begin{array}{l}\text { Time to two segment } \\
\text { regression (min) }\end{array}$ & $\begin{array}{l}132.33 \pm \\
48.29\end{array}$ & $\begin{array}{l}148.77 \pm \\
48.89\end{array}$ & $\begin{array}{l}171.57 \pm \\
25.46\end{array}$ & 0.002 & 0.286 & 0.001 & 0.093 \\
\hline $\begin{array}{l}\text { Duration of surgery } \\
\text { (min) }\end{array}$ & $\begin{array}{l}102.27 \pm \\
32.48\end{array}$ & $\begin{array}{l}99.73 \pm \\
29.17\end{array}$ & $\begin{array}{l}106.03 \pm \\
26.07\end{array}$ & 0.706 & 0.985 & 0.946 & 0.763 \\
\hline
\end{tabular}

Table 3: Maximum sensory level (MSL) Data given as frequency (\%)

$\begin{array}{lllll}\text { MSL } & \begin{array}{l}\text { Groups } \\ \text { Group A }\end{array} & \text { Group B } & \text { Group C } & \text { value } \\ \text { T4 } & 0(0.0 \%) & 1(3.3 \%) & 12(40.0 \%) & < \\ \text { T6 } & 8(26.7 \%) & 8(26.7 \%) & 10(33.3 \%) & 0.001 \\ \text { T7 } & 3(10.0 \%) & 9(30.0 \%) & 6(20.0 \%) & \\ \text { T8 } & 9(63.3 \%) & 12(40.0 \%) & 2(6.7 \%) & \\ \text { Total } & \mathbf{3 0 ( 1 0 0 \% )} & \mathbf{3 0 ( 1 0 0 \% )} & \mathbf{3 0 ( 1 0 0 \% )} & \end{array}$

(Table 4). There was a similar dose related prolongation in the duration of motor blockade (DMB) in Group C as compared to Group B and Group A respectively. Dose related prolongation was highly significant among all the groups with $\mathrm{P}<0.001$ (Table 4).

Likewise, the duration of analgesia was significantly prolonged among the groups as the dose of dexmedetomidine increased as indicated by the time of first rescue analgesia. A highly significant difference was found with respect to duration of analgesia between all three groups $(\mathrm{P}<0.001)$ (Figure 1). Group $\mathrm{C}$ required significantly less rescue analgesics in the first 24 hours postoperatively than Group B $(\mathrm{P}<0.001)$ and 0.001). The time to rescue analgesia in Group A was $351.33 \pm$ 101.19, Group B $472.00 \pm 24.41$ and Group C $738.00 \pm$ 67.79 min respectively.

All the groups were comparable with respect to nausea, vomiting, urinary retention, and pruritus. Group C had higher incidence of sedation with highly significant difference between Group A vs B and Group B vs C at 4 $\mathrm{h}$ and significant difference between all three groups $(\mathrm{P}$ $<0.001$ ) at $8 \mathrm{~h}$ with a sedation score of 2 . However, no patient suffered from higher sedation scores i.e., 3 and 4 (Figure 2).

The incidence of bradycardia and hypotension were highest in Group C followed by Group B and A respectively; however, the difference was not statistically significance and none of the patient required rescue atropine for significant bradycardia.

\section{Discussion}

\begin{tabular}{l|l|l|l|l|l|l|l|l}
\hline Table 4: Motor Block Characteristics and Maximum Motor Block Achieved (Data given as Mean \pm SD) \\
\hline & Group A & Group B & Group C & P Value & $\begin{array}{l}\text { Group A } \\
\text { vs. B }\end{array}$ & $\begin{array}{l}\text { Group A } \\
\text { vs. C }\end{array}$ & $\begin{array}{l}\text { Group B } \\
\text { vs. C }\end{array}$ \\
\hline OMB (sec) & $234.50 \pm 20.48$ & $\begin{array}{l}229.83 \pm \\
14.59\end{array}$ & $\begin{array}{l}187.23 \pm \\
3.12\end{array}$ & $<0.001$ & 0.677 & $<0.001$ & $<0.001$ \\
\hline DMB (min) & $255.53 \pm 44.25$ & $312 \pm 29.64$ & $\begin{array}{l}361.4 \pm \\
16.14\end{array}$ & $<0.001$ & $<0.001$ & $<0.001$ & $<0.001$ \\
\hline Maximum motor block (Bromage scale) & & & & & \\
\hline 2 & $0(0.0 \%)$ & $2(6.7 \%)$ & $0(0.0 \%)$ & & & \\
\hline 3 & $30(100 \%)$ & $28(93.3 \%)$ & $30(100 \%)$ & 0.129 & & \\
\hline Total & $30(100 \%)$ & $30(100 \%)$ & $30(100 \%)$ & & & \\
\hline
\end{tabular}


In our study we analyzed 3 different doses of intrathecal dexmedetomidine, $2.5,5$ and $10 \mu \mathrm{g}$ as an adjunct to $0.5 \%$ hyperbaric bupivacaine to determine the optimum intrathecal dosage that provides maximum duration of intraoperative anesthesia and postoperative analgesia, while producing minimal side effects. A dose dependent decrease in onset time with increase in duration of sensory block and time to rescue analgesia was noted with statistically significant difference between the three groups. In our study highly significant difference was found with respect to duration of analgesia between all three groups $(\mathrm{P}<0.001)$. Time to regression of two sensory dermatomes from the peak sensory block level), an important end point of our study was observed to increase with the incremental IT dexmedetomidine dose. There was a highly significant difference with respect to TSSRT between Group A vs. C. These findings can be attributed to spinal cord level activation of both alpha-2c and alpha-2a receptors in the neurons of superficial dorsal horn, especially lamina 2 by dexmedetomidine, resulting in decreased pain transmission by suppressing the release of pro-nociceptive transmitters - substance $P$ and glutamate, from primary afferent terminals, and by hyperpolarizing spinal interneurons via $G$ protein mediated activation of $\mathrm{K}+$ channels. ${ }^{6}$ Sensory parameters of our study were comparable to previous studies. ${ }^{1,3,7,8}$ Naaz et al. found that all patients receiving intrathecal dexmedetomidine had lesser postoperative pain scores and longer duration of analgesia. ${ }^{4}$ This effect was more pronounced as the dose of dexmedetomidine increased.

Highest block level was attained in Group C. Block level is influenced by total dosage of local anesthetic (LA). LA dose was constant across all the groups with incremental dose of dexmedetomidine. We observed that the OSB was dose dependent. Similar results were found by multiple investigators who observed early OSB with higher IT dexmedetomidine doses. .,7,8,9,10 $^{2}$

Our research revealed, onset of motor block was significantly earlier in group with the highest dexmedetomidine dose. Various studies have demonstrated onset of motor block having a dose dependent effect. ${ }^{11}$ Though the difference in the quality of motor block between the three groups in our research was not significant, there existed significant variability across the groups in the duration of motor block. Various explanations have been postulated for this:

1). An additive or synergistic effect to the local anesthetics, or due to the interference with neuromuscular activity, or binding of alpha- 2 agonists to motor neurons in the dorsal horn. ${ }^{12}$

2). Direct impairment of excitatory amino acids release from the spinal interneurons. ${ }^{13}$
3). Binding of these agonists to motor neurons in the dorsal horn of the spinal cord. ${ }^{13}$

Similar results were reported by previous two studies regarding a dose-dependent decrease in motor block onset time with increasing dose of intrathecal dexmedetomidine. . $^{3,10}$

In contrast, the some other researchers did not observe significant dexmedetomidine dependent difference in motor onset time. .,15 $^{7}$

Most common side effect that have been observed by different investigators include sedation, hypotension and bradycardia. ${ }^{2,3}$ In our study none of the patients had nausea/vomiting or urinary retention, while no patient suffered from sedation score higher than 2 on Ramsay sedation scale.

Absence of significant sedation can be explained by the sparing of supraspinal central nervous system sites from excessive drug exposure. ${ }^{1,6}$ Occurrence of bradycardia and hypotension is due to postsynaptic activation of central alpha- 2 adrenoceptors resulting in sympatholytic effect, an effect that can be judiciously used to attenuate the stress response of surgery. The initial hypertensive phase is due to alpha $2 \mathrm{~B}$ adrenergic receptors, whereas hypotension is mediated by the alpha $2 \mathrm{~A}$ adrenergic receptors. $^{4}$

The demographic parameters and baseline vitals were comparable in all the three groups in our study. No significant differences were observed between $\mathrm{HR}$, MAP, $\mathrm{SpO}_{2}$, and respiratory rates the three groups $(\mathrm{P}<$ $0.5)$.

\section{Limitations}

The number of subjects enrolled in the study was comparatively small, as the sample size was based on previous studies involving lower doses. Also the COVID pandemic restricted the number of elective surgeries. The study also lacked a placebo/ control group. The reason for exclusion of placebo/control group was because we aimed to compare the different dosages of ITD.

\section{Conclusion}

According to our study, $10 \mu \mathrm{g}$ of intrathecal dexmedetomidine added to $0.5 \%$ hyperbaric bupivacaine significantly prolongs the duration of sensory block, motor block, and analgesia with minimal non-significant side effects over lower doses.

\section{Conflict of interests}

Authors declare no conflict of interests.

\section{Authors” contribution}


AM, VS: Concept, conduction of the study work and manuscript editing

AP, CK: Manuscript editing

\section{References}

1. Shaikh SI, Dattatri R. Dexmedetomidine as an adjuvant to hyperbaric spinal bupivacaine for infra-umbilical procedures: $A$ dose related study. Anaesth Pain Intensive Care 2014;18:180-5. [Free Full Text]

2. Koolwal $\mathrm{P}$, Baj B, Madani K M, Somani M, Mathur V. Dose related prolongation of hyperbaric bupivacaine by dexmedetomidine in lower abdominal and limb surgeries requiring spinal anaesthesia $A$ randomized double blind controlled study. IOSR-JDMS. 2015;14(7):584-90. [Free Full Text]

3. Gupta M, Gupta P, Singh DK. Effect of 3 different doses of intrathecal dexmedetomidine $(2.5 \mu \mathrm{g}, 5 \mu \mathrm{g}$, and $10 \mu \mathrm{g})$ on subarachnoid block characteristics: a prospective randomized double blind dose-response trial. Pain Physician. 2016 Mar;19(3):E411-20. [PubMed]

4. Naaz S, Bandey J, Ozair E, Asghar A. Optimal dose of intrathecal dexmedetomidine in lower abdominal surgeries in average indian adult. J Clin Diagn Res. 2016 Apr;10(4):UC0913. [PubMed] DOI: $10.7860 / J C D R / 2016 / 18008.7611$

5. Singh AP, Chawla S, Bajwa SJS, Khanna M. Efficacy and safety of dexmedetomidine as an Intrathecal agent: A dose finding clinical study. Anaesth Pain Intensive Care. 2017;21(1):13-18. [Free Full Text]

6. Sudheesh K, Rao RR, Kavya M, Aarthi J, Rani DD, Nethra SS. Comparative study of two doses of intrathecal dexmedetomidine as adjuvant with low dose hyperbaric bupivacaine in ambulatory perianal surgeries: A prospective randomised controlled study. Indian J Anaesth. 2015 Oct;59(10):648-52. [PubMed] DOI: 10.4103/0019-5049.167485

7. Kapinegowda ST, Anandswamy TC, Narayanappa VH, Kumar $S$, Hatti P. To compare the effects of different doses of dexmedetomidine on intrathecal bupivacaine in infraumbilical surgeries: a prospective, randomized, double-blind clinical study. Anesth Essays Res. 2017 Oct-Dec;11(4):847-853. [PubMed] DOI: 10.4103/aer.AER_257_16
8. Eid HEA, Shafie MA, Youssef HY. Dose-related prolongation of hyperbaric bupivacaine Spinal anesthesia by dexmedetomidine. Ain Shams J Anesthesiol. 2011;4:83-95.

9. Yektaş A, Belli E. The effects of $2 \mu \mathrm{g}$ and $4 \mu \mathrm{g}$ doses of dexmedetomidine in combination with intrathecal hyperbaric bupivacaine on spinal anesthesia and its postoperative analgesic characteristics. Pain Res Manag. 2014 MarApr;19(2):75-81. [PubMed] DOI: 10.1155/2014/956825

10. Halder S, Das A, Mandal D, Chandra M, Ray S, Biswas MR, et al. Effect of different doses of dexmedetomidine as adjuvant in bupivacaine -induced subarachnoid block for traumatized lower limb orthopaedic surgery: a prospective, double-blinded and randomized controlled study. J Clin Diagn Res. 2014 Nov;8(11):GC01-6. [PubMed] DOI: 10.7860/JCDR/2014/9670.5118

11. Zhang $Y$, Shan Z, Kuang L, Xu Y, Xiu H, Wen J, et al. The effect of different doses of intrathecal dexmedetomidine on spinal anaesthesia: a meta-analysis. Int $J$ Clin Exp Med. 2016;9(10):18860-86. [Free Full Text]

12. Chattopadhyay I, Banerjee SS, Jha AK, Basu S. Effects of intrathecal dexmedetomidine as an additive to low-dose bupivacaine in patients undergoing transurethral resection of prostate. Indian J Anaesth. 2017 Dec;61(12):1002-1008. [PubMed] DOI: 10.4103/ija.IJA_324_16

13. Mohamed T, Susheela I, Balakrishnan BP, Kaniyil S. Dexmedetomidine as adjuvant to lower doses of intrathecal bupivacaine for lower limb orthopedic surgeries. Anesth Essays Res. 2017 Jul-Sep;11(3):681-685. [PubMed] DOI: 10.4103/aer.AER_243_16

14. Bhure AR, Marodkar KS, Pramanik SB. A comparative study of two doses of intrathecal dexmedetomidine $10 \mathrm{mcg}$ and $15 \mathrm{mcg}$ as adjuvants to $0.5 \%$ hyperbaric bupivacaine for abdominal hysterectomy: A randomized, prospective, double blind study. Int J Basic Clin Pharmacol. 2016;5:2215-21. DOI: 10.18203/23192003.ijbcp20163264

15. Choudhary N, Patel A, Shah J, Efficacy of dexmedetomidine as intrathecal adjuvant in subarachnoid block and postoperative analgesia. Indian J Clin Anaesth. 2017;4(2):219-224. [Free Full Text] 